$0 \quad$ Authors Queries

Journal: Clinical Linguistics \& Phonetics

Paper: 317481

Title: Acoustics characteristics of voice and vocal care in acting and other students

Dear Author

During the preparation of your manuscript for publication, the questions listed below have arisen. Please attend to these matters and return this form with your proof. Many thanks for your assistance

\begin{tabular}{|l|l|l|}
\hline $\begin{array}{l}\text { Query } \\
\text { Reference }\end{array}$ & Query & Remarks \\
\hline 1 & $\begin{array}{l}\text { Define reason for bold numbers } \\
\text { within Table II. }\end{array}$ & \\
\hline 2 & $\begin{array}{l}\text { Define reason for bold numbers } \\
\text { within Table III. }\end{array}$ & \\
\hline 3 & $\begin{array}{l}\text { A declaration of interest statement } \\
\text { reporting no conflict of interest has } \\
\text { been inserted. Please confirm the } \\
\text { statement is accurate. }\end{array}$ & \\
\hline 4 & Date website accessed? & \\
\hline 5 & Initials? & \\
\hline 6 & Full journal title needed. & \\
\hline
\end{tabular}




\title{
Acoustics characteristics of voice and vocal care in acting and other students
}

\section{GORDANA VAROŠANEC-ŠKARIĆ}

University of Zagreb, Zagreb, Croatia

(Received 26 October 2006; accepted 2 November 2007)

\begin{abstract}
Based on voice-history data, a $\chi^{2}$ test was used to investigate the difference between students of acting $(n=45)$ and other students $(n=45)$. A $t$-test was used to calculate the differences in acoustic parameters between the two groups. It was expected that students of acting spent significantly more time practicing voice exercises, took more acting instructions, and generally spoke more in larger rooms and did warm up exercises $(\mathrm{p}<.001)$. However, it was not expected that they smoked more than non-professionals $(\mathrm{p}=.003)$, and that they drank alcoholic drinks as much as other students. Male students of acting had significantly lower $f_{0}$ SD means $(\mathrm{p}=.015)$, which means that they had a more stable pitch throughout phonation. Students of acting also showed a significantly higher Harmonics-to-Noise Ratio (HNR) than other students ( $p=.001$ for males; $p=.01$ for females). The data showed the importance of the appropriate use of voice, which reflected relatively good voice quality despite the bad living habits of the future professional voice users.
\end{abstract}

Keywords: Voice care, students of acting, regular students, acoustic characteristics

\section{Introduction}

Voice trainers, phoneticians, and voice pathologists agree that in order to prevent vocal difficulties, regular training and voice practicing is necessary in vocal occupations such as singing and acting (Sataloff, Spiegel, Hawkshaw, and Heuer, 1994). Professional actors must acquire knowledge about their vocal mechanism and how to protect their voice from damage when performing in more vocally demanding parts (Emerich, Titze, Švec, Popolo, and Logan, 2005). Therefore, the actor's voice is the target of much research, such as the assessment of perceptive dimensions of phonetic categories of voice setting and acoustic characteristics of voice timbre before and after voice and pronunciation exercises (Varošanec-Škarić, 2003), the evaluation of the voice range profile in sustained phonation and while reading dramatic texts in a studio environment and on stage (Emerich et al., 2005), and the comparison of acoustic characteristics of the actor's voice before and after a performance (Ferrone, Leung, and Ramig, 2004). A number of questionnaires in relation to voice protection were carried out and the results analysed. The questionnaires assessed the vocal habits and vocal hygiene of young choir singers (Tepe, Deutsch, Sampson,

Correspondence: Gordana Varošanec-Škarić, University of Zagreb, Faculty of Humanities and Social Sciences, Department. of Phonetics, HR-10000 Zagreb, Croatia. E-mail: gvarosan@ffzg.hr

ISSN 0269-9206 print/ISSN 1464-5076 online (C) 2008 Informa UK Ltd

DOI: $10.1080 / 02699200802173151$ 
0 Lawless, Reilly, and Sataloff, 2002), the effects of voice warm-ups for singers (e.g. physiological effects; Elliot, Sundberg, and Gramming, 1995), effects on voice quality in acoustic measures (Amir, Amir, and Michaeli, 2005), and the effects of voice warm-ups in objective analysis on a random sample of students (Vintturi, Alku, Lauri, Sala, Sihvo, and Vilkman, 2001). The pragmatic purpose of this research is to point at the objective parameters that give information about the current condition of their voice, on the basis of values above pathological threshold (if any).

\section{Method}

Subjects

A total of 90 subjects were recorded, 43 male (21 students of acting and 22 other students) and 47 female (24 students of acting and 23 other students). The students of acting $(n=45)$ were students of the Academy of Drama at the University of Zagreb and International Study of Acting and Puppetry at the University of Osijek. Other students were students of Faculty of Humanities and Social Sciences at the University of Zagreb. The average age of all actors (male and female) was 21.07 years; for all students, the average age was 20.64 years. The group of acting students had a larger age dispersion $(\mathrm{SD}=2.40)$ than the other students $(S D=1.67)$. The average age for male actors was 21.9 , ranging from $18-27$. The average age for the other students was 20.5 years, ranging from $18-26$. The average age for female actresses was 20.33, ranging from 18-24, and 20.78 in the range from $20-24$ for other female students.

\section{Voice history questionnaire}

The voice history questionnaire for professional voice users was adapted according to the 'Patient History Questionnaire for the Professional Voice User' (Ford, 1994: 356-360). The voice status form consists of five units which cover the description of the problem, past voice history, past medical history, personal lifestyle, and voice use.

Recording

After filling out the questionnaire, the acting students and the other students recorded three phonations of the vowel /a/ with a comfortable tone and loudness, at a distance of $30 \mathrm{~cm}$ from the microphone and in a studio environment. The measure of acoustic voice characteristics on phonation of the vowel /a/ is the customary procedure in measuring actors' voices (Varošanec-Škarić, 2003; 2005; Ferrone et al., 2004). For the purpose of this research, speech while acting students were playing a role was not recorded because it is natural that profiles of voice range in sustained phonation are different from emotional scene speech because of the larger pitch and loudness range (Emerich et al., 2005).

\section{Acoustic parameters}

Acoustic parameters were analyzed on the basis of the middle 3 seconds of three phonations of the vowel $/ \mathrm{a} /(3 \times 3 \mathrm{~s})$ with a comfortable tone and loudness. Average values of the mean, minimum, and maximum $f_{0}$, the standard deviation of $f_{0}$, local jitter $(\%)$ and shimmer 
$0 \quad(\mathrm{~dB})$, and the degree of acoustic periodicity (i.e. Harmonics-to-Noise Ratio-HNR in dB) were calculated using PRAAT software (Boersma and Weenink, 2006).

\section{Statistical analysis}

A $\chi^{2}$-test was used to analyse the difference between students of acting $(n=45)$ and other students $(n=45)$. The analysed variables were past voice history, past medical history, personal lifestyle, and voice use. Differences between groups based on the acoustic parameters were analysed by means of a $t$-test.

\section{Results}

\section{Results of the $\chi^{2}$-test based on voice history between groups of acting students and other students}

It was shown that groups of acting students significantly differ from the group of other students in the categories of voice use $(p<.0001$ in six dimensions $)$, past voice history $(\mathrm{p}<.001$ in two dimensions, and $\mathrm{p}<.05$ in two dimensions), personal lifestyle $(\mathrm{p}<.05$ in two dimensions) and in one dimension of past medical history $(\mathrm{p}<.05)$. (The arrangement is shown in Table I.) About half of all students had a voice problem and there was no statistically significant difference between the groups.

In past medical history, the groups significantly differed in the dimension of visits to voice and speech pathologists. Significantly more acting students visited a voice pathologist

Table I. Arrangement according to significance of the difference.

\begin{tabular}{|c|c|c|}
\hline & $\mathrm{p}$ & Direction \\
\hline Physician for the voice & $<.0001$ & actors $>$ students \\
\hline Speaking in large rooms & $<.0001$ & actors $>$ students \\
\hline Taking voice instructions & $<.0001$ & actors $>$ students \\
\hline Taking acting instructions & $<.0001$ & actors $>$ students \\
\hline Acting in plays & $<.0001$ & actors $>$ students \\
\hline Currently taking voice or acting instructions & $<.0001$ & actors $>$ students \\
\hline Speech-language pathologist & $<.0001$ & actors $<$ students \\
\hline Warming up before performing & .00032 & actors $>$ students \\
\hline Smoking & .00310 & actors $>$ students \\
\hline Symptoms - neck muscle tension & .00535 & actors $<$ students \\
\hline Speaking on television or radio & .01310 & actors $>$ students \\
\hline Illnesses & .02039 & actors $>$ students \\
\hline Symptoms-loss of voice & .02490 & actors $>$ students \\
\hline Coaching a sport & .02490 & actors $>$ students \\
\hline Physical activities & .02963 & actors $>$ students \\
\hline Playing an instrument & .05385 & actors $>$ students \\
\hline Last meal & .06474 & actors $>$ students \\
\hline Solo singing & .07364 & actors $>$ students \\
\hline Symptoms - constant throat clearing & .08198 & actors $<$ students \\
\hline Cheerleading & .09161 & actors $<$ students \\
\hline Medications & .16290 & actors $<$ students \\
\hline Allergies & .26737 & actors $<$ students \\
\hline Voice problems & .52668 & actors $>$ students \\
\hline Coffee or caffeinated tea & .59816 & actors $<$ students \\
\hline Alcohol & .77730 & actors $>$ students \\
\hline Caffeinated soda & 1.00000 & actors $=$ students \\
\hline
\end{tabular}


$0 \quad(\mathrm{p}<.0001)$ while other students visited a speech pathologist $(\mathrm{p}<.001)$. However, this difference is expected and does not say anything about possible voice problems in students of acting or about voice disorders of other students. This is because students of acting are obliged to take a voice pathology examination in the first semester of their first year of study, and in the group of students of acting, about half of the sample were students of phonetics who during their study have a one-semester course with a speech pathologist whom they attend observation classes with. Naturally, this makes students of acting more aware of the need to take care of their voices during further education. Students of acting take preventative action when they notice problems with their voice, or if other teachers refer them for a voice pathology examination, or if they notice that voice fatigue occurs, resulting in periods of hoarseness. They mostly responded that they went to see a physician to learn preventative measures and throat control, and for past cases of laryngitis. The phonetician also referred them to such an examination if the measured acoustic parameters of voice quality surpassed or just reached the threshold of pathology (e.g. the measure of the pathological threshold of shimmer and jitter). It is interesting that other students had more problems with tension in the neck muscle than actors $(p=.005)$, while students of acting had significantly more symptoms of voice loss, which could be accounted for by the difference of the type of their study. Students of acting are more active, even during classes, because of exercises in artistic subjects (daily classes in acting and scene speech) and physical skills (scene movement), while other students mostly sit during classes and while studying and preparing essays. Other students clear their throat (coughing and the like) slightly more than actors $(\mathrm{p}=.08)$. It can be said that the avoidance of throat clearing using sound adaptors is a piece of phonetic advice which is easier to apply to actors.

Concerning allergies and taking medication, there was no difference between the group of actors and other students. However, it is interesting that actors had more illnesses with less reliability $(p=.02)$. Looking at gender, women indicated twice as many allergies as men, which is normal. Actors had slightly more laryngitis, which could be explained by the fact that they use speech in a more expressive way, which is probably why they are more sensitive to laryngitis. Since the cause of illness was not tested, it is possible that the difference occurred due to their increased health sensibility (i.e. they visit doctors regularly when they notice such difficulties), which they indicated as mostly chronic difficulties (e.g. laryngitis, sinusitis, angina, bronchitis). Two vocal professionals had an examination (one being a singer and one an actress) because of a dry mucous membrane of the throat and a dry cough. Other students had similar illnesses, and if they specified laryngitis they did not specify it as a chronic problem. Two students who specified cold and laryngitis as acute were excluded from acoustic measurements so that the result between the groups could be comparable.

The following contains the results regarding voice use and personal lifestyle. Results based on the $\chi^{2}$-test that met expectations included that students of acting train their voices (e.g. voice instructions, acting instructions such as scene speech) significantly more, act in plays, and therefore speak more often in large rooms $(\mathrm{p}<.0001)$, do more warm up exercises before public appearance (e.g. before acting, singing, acting lessons) $(p=.0003)$, speak more on $\mathrm{TV}$ or radio $(\mathrm{p}=.01)$, and practice solo singing non-signficantly more $(p=.07)$. However, the data that future elite vocal professionals and students of acting smoke more than other students, in spite of the fact that they were given instructions on voice care, is surprising $(\mathrm{p}=.003)$, as is the data that they drink as many alcoholic and caffeinated drinks as other students. Additional $t$-test analyses showed that male students drink significantly more alcohol than female students $(p=.001)$, three times as many drinks 
a week (3.2:1.26). Acting students eat their last meal slightly later $(\mathrm{p}=.064)$, on average around 9:08 pm as compared to 8:25 pm for other students. However, the median of the last meal of actors shows a later time; actors gather together around 9:00 pm (13), while 16 of them eat between 10-12 pm, and for students the median is at $8 \mathrm{pm}$ (11). Therefore, it can be concluded that actors take their last meal too late, considering the fact that possible negative consequences should not be ignored (i.e. reflux, which can produce morning hoarseness) (Tepe et al., 2002). The question arises as to how poor lifestyle habits, which are not in accordance with voice care, influence the acoustic voice quality parameters. On the other hand, acting students show a tendency of active involvement in sports activities, so in the category of voice use they significantly participate more in sports teaching $(\mathrm{p}=.02)$, and in the category of personal lifestyle they participate more in physical activities $(\mathrm{p}=.029)$, while other students are non-significantly more prone to loud cheerleading $(\mathrm{p}=.09)$.

\section{Results of the acoustic analysis and difference between the groups, based on the t-test}

Comparison of acoustic variables between the group of future actors and other students. The results show that male students of acting have a significantly higher harmonic-to-noise ratio (Table II: $24.06 \mathrm{~dB} ; \mathrm{p}=.001$ ). Further, male actors have significantly lower average deviations of $f_{0}(p=.015)$. As all standard deviations of $f_{0}$ were taken into account, one can conclude that acting students' tone is more stable during whole phonation than that of other male students. Standard deviation of fundamental frequency from the middle of phonation is just slightly lower for actors. Average $f_{0}$ values of both male groups are about equal, $\sim 116 \mathrm{~Hz}$, and have similar minimum and maximum values, but with slightly higher maximal $f_{0}$ values on average than other students. Jitter (in per cent) is, on average, twotimes lower in the group of male actors, but that difference is not significant $(0.288 \%$ : $0.577 \% ; \mathrm{p}=.06)$, and it is also obvious that average jitter dispersion is lower in the group of actors. Shimmer (in $\mathrm{dB}$ ) is slightly lower in the group of actors.

Table II. Average values of acoustic variables (Praat): difference between the group of acting students and other students based on a $t$-test (male and female subjects).

\begin{tabular}{|c|c|c|c|c|c|c|}
\hline & \multicolumn{2}{|c|}{ Actors } & \multicolumn{2}{|c|}{ Students } & \multicolumn{2}{|c|}{$t$-test } \\
\hline & Mean & $\mathrm{SD}$ & Mean & $\mathrm{SD}$ & $\mathrm{p}$ & $T$ \\
\hline \multicolumn{7}{|l|}{ Male } \\
\hline Mean $f_{0}(\mathrm{~Hz})$ & 116.334 & 18.913 & 116.851 & 19.988 & .931 & .087 \\
\hline $\operatorname{SD} f_{0}$ & .964 & .306 & 1.531 & .968 & .015 & 2.523 \\
\hline Min. $f_{0}$ & 113.958 & 18.684 & 113.305 & 19.326 & .911 & .113 \\
\hline Max. $f_{0}$ & 118.848 & 19.213 & 122.082 & 21.752 & .608 & .516 \\
\hline Jitter (\%) & .288 & .080 & .577 & .681 & .061 & 1.914 \\
\hline Shimmer (dB) & .265 & .190 & .302 & .163 & .497 & .684 \\
\hline $\mathrm{HNR}(\mathrm{dB})$ & 24.060 & 2.697 & 20.891 & 2.914 & .001 & 3.649 \\
\hline \multicolumn{7}{|l|}{ Female } \\
\hline Mean $f_{0}(\mathrm{~Hz})$ & 207.940 & 22.162 & 210.408 & 26.523 & .739 & .336 \\
\hline $\operatorname{SD} f_{0}$ & 2.889 & 7.659 & 5.315 & 12.824 & .455 & .754 \\
\hline Min. $f_{0}$ & 202.216 & 30.815 & 200.550 & 41.011 & .880 & .152 \\
\hline Max. $f_{0}$ & 212.460 & 18.994 & 218.946 & 22.438 & .305 & 1.036 \\
\hline Jitter (\%) & .268 & .120 & .356 & .162 & .058 & 1.944 \\
\hline Shimmer (dB) & .199 & .114 & .257 & .087 & .075 & 1.818 \\
\hline $\mathrm{HNR}(\mathrm{dB})$ & 25.877 & 3.619 & 23.179 & 2.966 & .011 & 2.639 \\
\hline
\end{tabular}


0 It is interesting that female students of acting have significantly higher HNR than other female students $(p=.01$; Table II), meaning that they have more harmonic tone. It can be seen that jitter is non-significantly lower in the group of actresses $(.268: .356 ; p=.058)$, and shimmer is as well (in $\mathrm{dB})(.199: .257 ; \mathrm{p}=.075)$. The average value of fundamental frequency (in $\mathrm{Hz}$ ) on the basis of phonation of $/ \mathrm{a} /$ is about equal to that of other students (207.9:210.4), and lower values of average dispersions of $f_{0}$ show that that their tone is more stable than that of other female students, although not as significantly as in the case of male students.

Smoker's and non-smoker's voices. Male smokers have significantly lower average values of $f_{0}$ and minimal and maximal values of $f_{0}$ than non-smokers $(p<.01)$, and non-significantly lower HNR and higher average values of local jitter (.51:.34\%) and shimmer (.29:.27 dB) than non-smokers (Table III). Those higher average values are below the pathological threshold for local jitter $(1.040 \%)$ and local shimmer $(.350 \mathrm{~dB})$. Female smokers have significantly lower average maximal values of $f_{0}$ than non-smokers $(p=.04)$, nonsignificantly lower average values of $f_{0}$ and minimal values of $f_{0}$, and smaller ranges of $f_{0}$. Unexpectedly, female smokers have about equal or slightly lower than average values of jitter and shimmer than female non-smokers, and HNR comparable to those of female non-smokers.

It is obvious that there is some difference between the results in acoustic parameters for female smokers and the results for male smokers and other students. That can be explained by the data describing how long and how often they smoke, and also how often they drink alcohol. Female smokers, on average, smoke for a shorter period (4.19:5.5 years), and they also smoke fewer cigarettes than male smokers (.61:.85 packs per day). Female smokers drink significantly less alcohol a week than male smokers $(p=.001)$. This is the probable reason for female smokers not exhibiting such differences in acoustic parameters in comparison with male smokers.

\section{Discussion}

Poor personal habits in future voice professionals, despite the instructions of their trainers and theoretical knowledge about the disadvantages of nicotine and alcohol, are not only characteristic of Croatian students. This can be seen in the research carried out by Timmermans, De Bodt, Wuyts, and Van de Heyning (2003; 2005), who tested the

Table III. Average values of acoustic variables (Praat): difference between the groups of smokers and non-smokers (male and female).

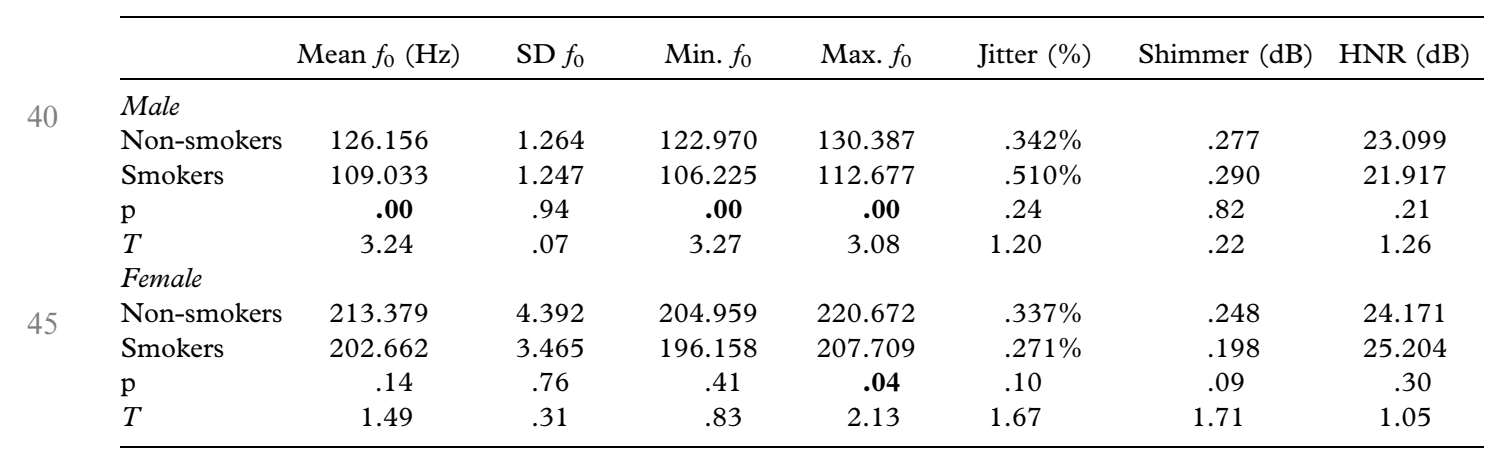


0 efficiency of voice exercises on 23 future vocal professionals, students of drama and radio directors. The research was conducted longitudinally, before and after voice training and education on vocal hygiene. In perceptual and objective analyses, voice quality improved after 18 months of work, but newly acquired knowledge did not have any influence on the prevention of smoking, vocal misuse (i.e. loud speaking), stress, and time of last meal. This research has shown that the most productive period for hoarseness treatment is 9 months, while perceptual evaluation, variables of jitter, and maximal phonation time turned out to be much better after 18 months of work. It is discouraging that after 18 months even more subjects reported smoking, stress, and eating late meals. Thanks to voice exercises (e.g. phonetic exercises for voice improvement), some perceptual dimensions of phonetic settings can be evaluated better even after a shorter period (Varošanec-Škarić, 2003), but, unfortunately, as this research has shown, it seems that instruction about voice care and hygiene does not prevent a bad personal lifestyle, because future actors continue to smoke, drink, and eat their last meal relatively late, despite knowing the disadvantages of such habits. Other researchers have also noticed that smoking is popular in artistic and media society (Raphael, 1991; Broaddus-Lawrence, Treole, McCabe, Allen, and Toppin, 2000; Timmermans et al., 2003; 2005), and some physicians notice the psychological lability and social insecurity caused by the actors' obligation that, because of the risk of losing a job, they cannot miss a performance and that despite laryngitis and other illnesses they must perform, which causes even more problems (Mitchell, 1994). This could partially be ascribed to the constant stress and to the individual personality of future artists, but also to the schedule of obligations during the present study, which in some ways makes a completely normal lifestyle impossible, especially concerning the time of last meal. There is a lack of balance between artistic talent and social achievement (i.e. media exposure, fame, and personal stability). The cause is not due to youth and immaturity, because that kind of poor personal lifestyle is characteristic of professional actors who are already famous. It seems that the personal lifestyle of future singers, who learn Western opera singing, is much better. This makes sense because the range of voice is extremely important for a good functional singing voice. They are ready to accept a proper personal lifestyle and quit smoking, drinking alcohol, and eating late meals (because of the danger of reflux). As there are only a few subjects included in the research on the singing voice, the statement above cannot be fully justified. Phoneticians are not the ones who will change bad life habits of future vocal professionals. Through the use of phonetic exercises (Škaric and Varošanec-Škarić, 1999), the phonetician should take care of the aesthetic quality of their voice.

Relatively good results for jitter, shimmer, and HNR within the group of actors and significantly better HNR in comparison with the group of other students can be accounted for by regular voice exercises. The research by Varošanec-Škarić (2003) shows that after voice exercises both male and female voices had non-significantly higher average values of

$40 \quad f_{0}$ and lower jitter, while male voices had lower shimmer as well, which can be explained by the fact that male voices usually have higher shimmer than female ones. Furthermore, voices that were evaluated as significantly more stable after the exercises turned out to have lower average values of shimmer and jitter based on the phonation of /a/; those evaluated as less hoarse had lower average jitter values, and female voices evaluated as significantly less noisy had lower average shimmer values. The research shows that phonetically designed voice exercises are effective, because even in a short period they can improve voice quality and positively influence the laryngeal and supralaryngeal setting. The research by Amir et al. (2005) shows that after vocal warm-up exercises frequency perturbation is significantly 
0 lower $(p<.001)$, perturbation of amplitude is slightly lower $(p<.05)$, while the amplitude of formants and HNR are higher $(\mathrm{p}<.05)$. This research also shows better results in the group of actors than in the group of other students. Although the difference is evident, it is not statistically significant, except for HNR of male and female voices of actors. This can be explained by the fact that the recording was not performed immediately after the warm-up exercises longitudinally, but in the same conditions. The students of acting have better results because of continuous voice exercises. This is shown by the fact that the data for HNR are significant when comparing students of acting with other students, and not between the groups of smokers and non-smokers, which would be expected to be more likely. The most significant results for male smokers were those concerning $f_{0}$, and the only

10 significant difference between male and female smokers was related to maximum $f_{0}$. The reason for no other significant differences in acoustic variables except for maximum $f_{0}$ can be explained by the fact that the number of male smokers $(24: 19)$ was larger than that female smokers (18:29). As stated above, the period of smoking and the number of cigarettes they smoke could also account for such results. Smoking contributes to the 15 perception of hoarseness, but in this research, that information was more often associated with the lower $f_{0}$ of male and female smokers in comparison with non-smokers. Since all of them were young people, it is understandable that significant differences for shimmer, jitter, and HNR could not be attained, but this indicates that smoking has more influence in a shorter period on lower frequency-area, fundamental frequency, and the range of $f_{0}$. Ferrone et al. (2004) concluded that proper voice use contributes to the stability of all acoustic measures when comparing them before and after performance in a play, and that there are no significant perceptual changes. Therefore, regular voice and warm-up exercises prevent the attested changes in voice quality, even after greater voice efforts, such as performance in a play.

\section{Conclusion}

Unfortunately, despite instruction on voice care, proper voice use and proper personal lifestyle of vocal professionals, which exclude smoking, alcohol, caffeinated and carbonated drinks, and late meals, students of acting have poor personal lifestyle habits just like other students. Concerning a poor personal lifestyle, male actors are a more endangered group than female actors. On the basis of comparison of the data about how long and how much they smoke and how much alcohol they drink, it can be concluded that maintaining a poor personal lifestyle could lead to voice quality that is even worse for future vocal professionals and other students.

Generally speaking, the data confirm the importance of proper voice use and care, which keep the voice quality of future actors in relatively good condition despite a poor personal lifestyle. An adequate vocal technique can help in the prevention of vocal misuse symptoms.

Declaration of interest: The author reports no conflicts of interest. The author alone is responsible for the content and writing of the paper.

\section{References}

Amir, O., Amir, N., \& Michaeli, O. (2005). Evaluating the influence of warmup on singing voice quality using acoustic measures. Fournal of Voice, 19, 252-260.

Boersma, P., \& Weenink, D. (2006). Praat: doing phonetics by computer [Computer program]. Available online at: http://www.praat.org/. 
Broaddus-Lawrence, P., Treole, K., McCabe, R., Allen, R., \& Toppin, L. (2000). The effects of preventive vocal hygiene education on the vocal hygiene habits and perceptual vocal characteristics of training singers. Fournal of Voice, 14, 58-71.

Elliot, N., Sundberg, J., \& Gramming, P. (1995). What happens during vocal warm-up? fournal of Voice, 9, $37-44$.

Emerich, K. A., Titze, I. R., Švec, J. G., Popolo, P. S., \& Logan, G. (2005). Vocal range and intensity in actors: a studio versus stage comparison. Fournal of Voice, 19, 78-83.

Ferrone, C., Leung, G., \& Ramig, L. O. (2004). Fragments of a Greek trilogy: impact on phonation. Fournal of Voice, 18, 488-499.

Ford, Ch. N. (1994). Phonosurgery. In M. Benninger, B. Jacobson, \& A. Johnson (Eds), Vocal arts medicine: The care and prevention of professional voice disorders (pp. 344-369). New York: Thieme Medical Publishers, Inc.

Mitchell, S. A. (1994). The professional speaking voice. In M. Benninger, B. Jacobson, \& A. Johnson (Eds), Vocal arts medicine: The care and prevention of professional voice disorders (pp. 169-176). New York: Thieme Medical Publishers, Inc.

Raphael, B. (1991). Special considerations relating to members of the acting profession. In R. Sataloff (Ed.), Professional voice. The science and art of clinical care (pp. 85-89). New York: Raven Press.

Sataloff, R. T., Spiegel, J. R., Hawkshaw, M. J., \& Heuer, R. J. (1994). Professional voice users: obtaining the history. In M. Benninger, B. Jacobson, \& A. Johnson (Eds), Vocal arts medicine: The care and prevention of professional voice disorders (pp. 72-78). New York: Thieme Medical Publishers, Inc.

Škarić, I., \& Varošanec-Škarić, G. (1999). Vježbe za glas i izgovor. In A. Bajc, K. Bucik, \& S. Janežič (Eds), Zbornik: Ustvarjalnost $v$ logopediji (pp. 197-200). Vipava: Center za usposabljanje invalidnih otrok Janka Premrla Vojka.

Tepe, E. S., Deutsch, E. S., Sampson, Q., Lawless, Reilly, J. S., \& Sataloff, R. T. (2002). A pilot survey of vocal health in young singers. Fournal of Voice, 16, 244-250.

Timmermans, B., De Bodt, M., Wuyts, F., \& Van de Heyning, P. (2003). Vocal hygiene in future professional voice users and in professional voice users. Logopedica Phoniatr. Vocol., 28, 127-132.

Timmermans, B., De Bodt, M. S., Wuyts, F. L., \& Van de Heyning, P. H. (2005). Analysis and evaluation of a voice-training program in future professional voice users. Fournal of Voice, 19, 202-210.

Varošanec-Škarić, G. (2003). Voice assessment before and after phonetic voice and pronunciation exercises. In M. J. Sole, D. Recasens, \& J. Romero (Eds), Proceedings of the 15th International Congress of Phonetic Sciences 2153-2156, Barcelona, 3-9 August 2003, Vol. 2. Adelaide: Causal Production Pty Ltd.

Varošanec-Škarić, G. (2005). Timbar. Zagreb: FF press.

Vintturi, J., Alku, P., Lauri, E.-R., Sala, E., Sihvo, M., \& Vilkman, E. (2001). Objective analysis of vocal warm-up with special reference to ergonomic factors. Fournal of Voice, 15, 36-53. 